\title{
Morar em Campinas. Usos e costumes (1850-1900)
}

\author{
To live in Campinas. Habits and customs (1850-1900) \\ Eliane Morelli Abrahão ${ }^{1}$ \\ eliane@cle.unicamp.br
}

Resumo

Analisam-se, no presente artigo, os usos e costumes compartilhados por alguns segmentos da sociedade paulista, especificamente Campinas, entre os anos de 1850-1900. Detenho-me aos espaços domésticos destinados ao convívio social, mas com um olhar que vai além da análise arquitetônica. Focalizo um dos domínios mais elucidativos da cultura, a casa. As informações sobre os modos de morar foram extraídas dos inventários post mortem o que possibilitou identificar processos de transmissão de bens de uma geração à outra, a opulência material dos residentes na cidade e corroborar a hipótese de que Campinas, na segunda metade do século XIX, vivenciou um processo de modernização e sofisticação nas formas de morar e receber convidados momentos de sociabilidade proporcionados pelos jantares e banquetes oferecidos pela elite cafeeira a seus pares.

Palavras-chave: Cultura material; Usos e costumes; Campinas (SP); História da alimentação.

\begin{abstract}
In this article, are analysed the habits and customs shared by some segments of São Paulo's society, specifically Campinas, between the years 1850 1900. Holding to the domestic spaces intended for social conviviality, with a look that goes beyond the architecture, the focus is one of the most relevant domains of culture, the house. The information on the ways of living were drawn from post-mortem inventories, that allowed identify the process of assets transfer from one generation to another, and the material opulence of the residents of the city. In this way, we corroborate the hypothesis that Campinas, in the second half of the 19th century, experienced a process of modernization and sophistication in the ways of living and receiving guests - moments of socialization provided by dinners and banquets offered by members of the coffee elite to their pairs.
\end{abstract}

Keywords: Material culture; Social customs; Campinas (SP); Food History.

1 Doutora em História pela Universidade Estadual de Campinas (Unicamp). Historiadora responsável pelos Arquivos Históricos do Centro de Lógica, Epistemologia e História da Ciência/Unicamp. 
Artigos

A importância de estudar o complexo casa, valendo-me de um termo utilizado por Gilberto Freyre (1979), vai além das questões arquitetônicas ou decorativas. Observar os espaços domésticos permite recuperar as atividades cotidianas e anônimas e conhecer aspectos reveladores da estrutura de uma sociedade. Ideia que coaduna com a posição de Fernand Braudel (1995, p.11-15), o qual afirma ser possível através dos "pormenores significativos", compreender as influências culturais incorporadas à sociedade estudada, em um determinado tempo cronológico, porque se adentra em um dos domínios mais elucidativos da cultura.

A casa é um espaço de representações, no qual os hábitos e costumes familiares espelham diretamente os valores culturais compartilhados pela sociedade. Como aponta Luce Giard (2000, p.203-7), o habitat confessa sem disfarce o padrão econômico, social e as ambições de vida de seus ocupantes. As normas de conduta adotadas nas cortes europeias, o ideal do petit-burgeois - contido, discreto, disciplinado e polido - funcionavam como códigos de comportamento seguidos tanto em casa quanto na vida pública, como apontou Norbert Elias (1994). Ritos e códigos propagados entre a elite local, com a chegada da família Real ao Brasil (1808), em um período marcado pela valorização das reuniões sociais, com festas realizadas nos recémconstruídos salões imperiais e nas grandes residências familiares, alterando os modos da sociedade do Rio de Janeiro e dos novos centros urbanos que foram surgindo, entre eles Campinas (RAINHO, 1995. p.139-152; COSTA, 2004, p.107).

Examinar Campinas e seus habitantes, sob a perspectiva da cultura material e das práticas alimentares, descortinou o processo de modernização vivenciado pela cidade e as mudanças de hábitos e costumes adotados pelas famílias em seus diferentes estratos. A imbricação desses dois componentes revelou o quanto as mulheres - representantes da aristocracia cafeicultora paulista - absorveram os padrões de comportamento adotados nas cortes europeias e os aplicaram no ato de receber convidados em seu próprio ambiente social. Apresentam especial interesse os cuidados que dedicavam à organização de suas casas, equipando-as com mobiliário, objetos decorativos e utensílios que serviam às ocasiões de sociabilidade alimentar.

Obviamente, o poder econômico favoreceu a elite agrária e outros segmentos da sociedade ao consumo de bens e à adoção de padrões de comportamento condizentes com seu pertencimento social. A sedução pelo status, possibilitada por ter salas bem decoradas, pelos serviços de mesa, café e chá, deixou para trás uma sobriedade dos costumes, e as casas deveriam corresponder à riqueza de seus proprietários (ABRAHÃO, 2015).

A urbe e seu entorno experimentaram um processo de modernização que se refletiu na implantação de serviços de infraestrutura, em mudanças na arquitetura das casas, nas formas de morar. A partir de 1840, os senhores de engenho iniciaram a construção de grandes sobrados urbanos destinados à moradia de fins de semana. Porém, com o desenvolvimento da cidade, as famílias dos fazendeiros e seus escravos "da casa" ocupam efetivamente suas residências urbanas (ABRAHÃO, 2007). Nas palavras de Celso Maria de Melo Pupo:

... as residências luxuosas que, de simples casas de fins-de-semana e festas religiosas, passaram a ser os lares amplos, cômodos, ricos, para a permanência da família em permuta com as fazendas, que passaram a ser o refúgio para descanso e férias (PUPO, 1969, p.156).

Nessa época, a Princesa do Oeste vivenciava seu apogeu econômico frente às outras cidades da província de São Paulo graças, inicialmente, à agroindústria do açúcar e depois com a cafeicultura. Sua localização privilegiada e a malha ferroviária implantada após 1872 agilizaram a comunicação com a capital da província e com o porto de Santos, fortalecendo suas funções agrícola e comercial (BAENINGER, 1996, p.13-33). A pujança da cidade foi relatada pelo viajante suíço J.J. Tschudi, em 1860, quando de sua visita a Campinas. Segundo ele:

Desde há muito tempo, Campinas se firmou como importante centro comercial de algumas comarcas distantes, tanto da província como também da de Minas Gerais, que para ela enviava seus produtos, tais como algodão, toucinho, feijão, queijo etc, recebendo em troca sal, ferramentas, artigos importados da Europa (TSCHUDI, 1980, p.178).

Quanto aos gêneros alimentícios, citados pelo viajante, as mulheres da elite poderiam adquirir na própria cidade, desde a década de 1870, presuntos, alféloa, champignons, petit-pois, azeite, amêndoas, chocolate francês, frutas em calda, vinhos, cervejas, água de flor de laranjeira, chá Hysson e até o queijo de Minas, 
conforme os anúncios publicados nos jornais de Campinas. O comércio local estava abastecido para atender a essa demanda, detalhe importante quando se leva em conta a viabilidade da feitura das receitas culinárias registradas por Anna Henriqueta de Albuquerque Pinheiro, casada com um membro da família dos Sousa Campos. Caso almejasse preparar o "Rocambole de camarão", ela encontraria o camarão seco ou fresco nos estabelecimentos comerciais da cidade (GAZETA, 2/3/1871, p. 3).

A modernização dos costumes é percebida nos ambientes da casa destinados a receber convidados, os quais serviam como uma "vitrine" da opulência e do bom gosto de seus moradores (ABRAHÃO, 2010). A "boa sociedade" brasileira buscava enquadrar-se nos padrões de uma nova civilidade e ser reconhecida pela aristocracia portuguesa, tendo como pano de fundo a "europeização" dos costumes, que se manifestava por meio do vestuário, dos gestos, da prática das boas maneiras e da etiqueta, enfatizando tudo o que a diferenciava dos outros estratos da sociedade local. Era imprescindível à "boa sociedade" adotar "[...] valores e modos europeus, civilizando os costumes, eliminando os ares coloniais.” (RAINHO, 2002, p.15). Ser "civilizado" era ser educado e levar a vida conforme se vivia nas metrópoles europeias, entre as quais Paris, citada frequentemente (HOMEM,1996, p.55).

Esse novo estilo de sociabilidade terá como principal resultado a construção de uma vida privada ligada à maior visibilidade pública, “[...] repercutindo na organização do espaço doméstico, na decoração requintada dos ambientes e nas novas formas de convivialidade." (SCHAPOCHNIK, 1998. p. 500-501). E antes de abordar o interior das residências e as práticas sociais adotadas pelas famílias de Campinas, faz-se necessário pensar, de maneira geral, a habitação e suas modificações.

A configuração da casa, no ocidente, permaneceu relativamente estável do século XII ao XV e, desde então, não parou de se transformar, de acordo com Philippe Ariès (1999, p.13). A introdução de novas soluções arquitetônicas fez surgir pequenos espaços, que a princípio eram apêndices dos aposentos principais, mas que logo conquistaram autonomia. São eles: gabinete, alcova, ruelle. ${ }^{2}$ A compartimentação do ambiente doméstico consolida, nas casas das elites, os ambientes públicos e privados (RANUM, 1999, p.214). Somando-se a isso a ideia de civilidade vem ampliar o significado do babitat, ou seja, o lar - home - identifica-se com tudo que está inserido na habitação. Nas palavras de Ariès (1999, p.16) essa mudança propiciou a "substituição de uma sociabilidade anônima - a da rua, do pátio do castelo, da praça, da comunidade - por uma sociabilidade restrita que se confunde com a família, ou ainda com o próprio indivíduo."

Nas residências campineiras identifica-se a existência de três espaços distintos para as atividades familiares. Uma parte da casa destinava-se ao convívio com pessoas não pertencentes à família, eram os espaços sociais, salas de estar, de jantar, sala de música, de jogos, a varanda, o alpendre; enquanto os oratórios e escritórios poderiam ser classificados como um espaço intermediário entre o público e o íntimo. A outra área, reservada à intimidade, incluía os quartos de dormir e as alcovas. O terceiro ambiente era destinado às atividades cotidianas e de funcionamento do lar, e compreendia os quartos de costura, salas de almoço e cozinha (ABRAHÃO, 2010, p.94 e 105).

É possível, mesmo sem ter em mãos as plantas dessas moradias, vislumbrar seu interior e a disposição dos ambientes, dadas as informações extraídas dos inventários post mortem (ABRAHÃO, 2010). No caso dos estratos mais ricos e das famílias de imigrantes com projeção social - por exemplo, os Krug, Faber, Florence e De Marco -, os avaliadores descreviam os objetos percorrendo cômodo a cômodo do domicílio. Exemplo disso é o rol de bens de Ana Matilde de Almeida, viúva do senhor José Rodrigues Ferraz do Amaral. Herdeira de propriedades urbanas e rurais, dentre eles o sítio Sete Quedas, também conhecido por Fazenda Sete Quedas, futura residência do Visconde de Indaiatuba. Os detalhes da construção de um de seus imóveis foram realçados pelo avaliador. Trata-se de casa situada na Rua da Cadeia (atual Rua Bernardino de Campos). Segundo a descrição, essa residência destacava-se das demais do logradouro por ser ampla, coberta com telhas de barro, possuir porta e quatro janelas de frente e outras quatro que davam para a travessa do fundo da mesma cadeia. O quintal divisava com a Rua Bairro Alto e com a travessa que fazia esquina com a casa de Damiana Alexandrina de Camargo, no valor de 3:836\$040 (TJC/CMU, 1.Of., 1844, Proc.2460. fl.8).

$\mathrm{Na}$ pretensão de Ana Matilde abrir sua casa à sociedade, ela dispunha de numerosos utensílios de louça, prata e vidro. Entre os descritos em seu espólio estavam:

2 Ruelle: espaço livre entre a cama e a parede. 
Artigos

aparelho louça pintada para chá no valor $14 \$ 000 ; 1$ dito chá azul usado para chá no valor $4 \$ 800$; 1 prato travesso 1 sopeira de louça branco no valor de 1\$600; 41 pratos de mesa brancos redondos usados 2\$050; 1 sopeira, 1 terrina usada branca no valor de $1 \$ 200 ; \ldots 1$ terrina pequena branca de louça, colher de mão, 1 bule branco, leiteira, 1 jarro, 2 tigelas, uma maior e outra menor tudo no valor de $1 \$ 500 ; 2$ compoteiras vidro sem tampa e sem prato no valor $4 \$ 000$; 1 ditas de vidro sem prato no valor de $2 \$ 000 ; \ldots 1$ colher de prata de sopa, no valor de 19\$520; 17 colheres de prata de mesa no valor de 49\$920; 18 colheres prata para chá, 1 açucareiro de prata no valor de 15\$120 (TJC/CMU, 1.Of., 1844, Proc.2460. fls.6-7).

Da construção aos interiores, as descrições possibilitam ao pesquisador identificar as formas de morar, o consumo de bens e os de hábitos das famílias estudadas. No caso, por exemplo, dos Sousa Campos - estreitamente ligados à fundação da Freguesia de Nossa Senhora da Conceição de Campinas de Mato Grosso -, nota-se que seus membros procuravam morar em padrão condizente com seu poderio econômico, conforme observado na equivalência dos valores dos móveis e utensílios, 1:535\$360 e 1:554\$650 respectivamente, acumulados pela matriarca Miquelina Dulce do Amaral, segunda esposa do major José de Sousa Campos (TJC/CMU, 3.Of., 1863, Proc.6980).

Trilhar o caminho desta família permitiu rastrear os diversos objetos de uso doméstico, preservados por gerações, inclusive alguns deles compõem o acervo do Centro de Memória - Unicamp (CMU). Essa Instituição foi escolhida por Theodoro de Sousa Campos Filho, o Theodorinho, para guardar e preservar a memória de sua família. Entre os objetos doados, estão candelabros de prata com as iniciais JSC (José de Sousa Campos), colheres e facas de prata, jogo com cinco facas com as iniciais TSC (Theodoro Sousa Campos) e toalhas de mesa, os quais constam dos inventários das senhoras Miquelina Dulce do Amaral e Maria Gertrudes de Sousa Campos, sua bisavó e avó, respectivamente. Entre os documentos cedidos ao CMU estão os três cadernos de receitas manuscritos de sua mãe, Anna Henriqueta de Albuquerque Pinheiro.

Perseguir os bens deixados por estas três mulheres do seio da família Sousa Campos exemplifica os padrões de comportamento adotados e perpetuados por elas em sua rede de relações. Para tanto, é importante traçar, de forma breve, a genealogia destas gerações. Do enlace entre o major José de Sousa Campos e Miquelina nasceram nove filhos, entre os quais José de Sousa Campos, também conhecido por Campinhos, no ano de 1830, em Campinas. Campinhos casou-se com Maria Gertrudes de Sousa Campos, sua prima-germana $^{3}$, em 19 de abril de 1851. O casal teve nove filhos, entre os quais Theodoro de Sousa Campos, batizado com 15 dias de vida em Campinas, no dia 9 de dezembro de 1865, marido de Anna Henriqueta (CAMPOS JR., 1940, p.305-316; LEME, 1903-1905, v.1, p.159-162).

$\mathrm{Na}$ residência da família Sousa Campos, por exemplo, presume-se que as recepções ocorriam com frequência dado a mobília e utensílios variarem em quantidade e individualidade. Miquelina Dulce do Amaral possuía pares de castiçais e serpentinas de prata, toalhas de mesa de linho e cambraia, novas e usadas, assim como outros objetos para uso nessas ocasiões especiais. Os aparelhos para chá e café compostos de bule, manteigueira, açucareiro, escaldadeira, cafeteira, leiteira, todos de prata, não faltaram de seu espólio. Havia ainda salvas, farinheiras de prata, faqueiro com caixa, colheres de sopa e chá, facas, garfos, açucareiro, tesoura de cortar com respectiva salva e paliteiro (TJC/CMU, 3.Of., 1863, Proc.6980. fl.21).

Caso esta matriarca, pelos idos de 1863, optasse por receber convidados para banquetes, tinha às mãos os objetos e alfaias necessários à ornamentação da mesa de jantar. $\mathrm{Na}$ descrição de seu espólio identifica-se:

1 par de serpentinas de prata em pouco uso pelo valor de $368 \$ 640 ; 2$ pares de castiçais de prata maiores pelo valor $227 \$ 841$; par de castiçais de prata no valor de $113 \$ 920$; par de moringas para mesa; toalha nova de linho para mesa no valor de $6 \$ 000$; toalha de algodão trançado para mesa no valor de $3 \$ 000$ (TJC/CMU, 3.Of., 1863, Proc.6980. fl.21).

É importante esclarecer que as serpentinas - tipo candelabro com mangas de cristal - eram raras nas casas paulistas dessa época. Localizamos quatro pares delas no valor total de $710 \$ 401$, descritos em seu espólio. Os castiçais eram peças mais comuns e eram fabricados com metal, estanho, casquinha, bronze, vidro, latão, madeira pintada ou dourada, ou mesmo com prata (ARAUJO, 2004, p.141).

A ambientação da sala de refeições do domicílio de Miquelina - equipada com relógio de parede,

3 Primo-germano: descendentes de dois irmãos e de duas irmãs. 
quadros, jarros de porcelana, aparadores, mesa de jantar e cadeiras, todos de cabiúna envernizados - ficava completa com os objetos destinados à alimentação, como descrito:

1 faqueiro de prata com caixa faltando uma colher, por 400\$000; 1 salva de prata maior, pesando 392 oitavas, por $141 \$ 120$; outra salva menor de prata, pesando 248 oitavas, por $89 \$ 280 ; 1$ par de farinheiras de prata, pesando 151 oitavas, por $54 \$ 360 ; 1$ tesoura de estrinchar [sic] com salva de prata pesando 73 oitavas, por $29 \$ 760 ; 1$ paliteiro de prata pesando 78 oitavas, por $28 \$ 080$ (...) (TJC/CMU, 3.Of., 1863, Proc.6980. fl.21).

Para o chá da tarde esta senhora dispunha de seu completo aparelho de prata para chá e café, composto de bule, manteigueira, açucareiro, escaldadeira, cafeteira e leiteira. Os saborosos biscoitos, bolos e sequilhos eram servidos devidamente arrumados em salvas de prata (TJC/CMU, 3.Of., 1863, Proc.6980. fl.20v; 2.Of., 1909, Proc.5837).

O mesmo cenário foi identificado na residência de Braulia Ludgera de Queiroz Sousa, casada com Francisco de Paula Sousa Campos, filho de Miquelina Dulce do Amaral. Entre a prataria havia:

paliteiro; castiçais; 18 colherinhas para chá; colher de prata para servir peixe; outra para arroz; espiritadeira (sic) com bandeja; concha para sopa; 20 colheres para sopa; 22 garfos; 14 facas; um par de trinchantes; pinça para tirar açúcar (TJC/CMU, 1.Of., 1895, Proc. 6115. fls.51-54v).

Enfim, Braulia possuía uma variedade de apetrechos de uso alimentar os quais atenderiam às refeições cerimoniosas que porventura organizasse em sua residência.

A criação de um ambiente dedicado especialmente às refeições na casa moderna do século XIX no ocidente indica a importância dessas ocasiões, para as altas classes europeias. Nesses momentos era fundamental conhecer e aplicar os rituais da alimentação, os protocolos de mesa. As elites locais, diante das mudanças políticas, econômicas e culturais, procuraram restabelecer uma posição social não mais embasada nos títulos de nobreza concedidos pelo regime imperial, mas adotando os padrões comportamentais europeus que passaram a vigorar no Brasil (SCHAPOCHNIK, 1998, p.440). Além disso, os sinais distintivos de status social - desde o gestual adequado às ocasiões públicas até o esmero material do preparar os banquetes, representado pelos utensílios e a estética das refeições - tornaram-se imprescindíveis para a demarcação de lugar do homem polido e bem-educado (LIMA, 1995). As boas maneiras em sociedade, entre eles os rituais à mesa, tornaram-se veículo de distinção, diferenciação e integração social (ABRAHÃO, 2010; PILLA, 2004, p.44).

Imaginam-se as práticas que a família de Cândida Maria Vasconcellos Barros, sogra de Hércules Florence, adotava em sua casa, vistas a quantidade de utensílios relacionados em seu espólio. Ela legou aos seus netos:

um aparelho de prata para café composto de: uma cafeteira, um bule, um açucareiro, uma manteigueira, um açucareiro mais [sic] pequeno, uma leiteira, uma tigela, tudo em bom uso, pesando 1.235 oitavas por $395 \$ 200$; um galheteiro de prata para servir de fruteira, pesando 83 oitavas por $23 \$ 560$; um paliteiro de prata, pesando 33 oitavas por $10 \$ 460$; doze colheres, doze garfos de prata marca F, pesando 377 oitavas por $120 \$ 640$; seis colheres e seis garfos de prata marca F, pesando 167 oitavas por $53 \$ 600$; uma concha de sopa prata em bom uso, com marca F, pesando 67 oitavas $21 \$ 440$; uma colher grande de prata para arroz em bom uso, marca F, pesando 39 oitavas $12 \$ 480$; doze facas de mesa com cabo de prata, marca F, por $42 \$ 000$; seis facas de mesa com cabo de prata, por $21 \$ 000$; uma colher de casquinha para peixes, por $4 \$ 000$; seis colheres e garfos de prata para sobremesa, pesando 180 oitavas por $38 \$ 720$; doze colherinhas de concha para açúcar, pesando 65 oitavas por 20\$800; uma campainha de prata, pesando 31 oitavas por $10 \$ 080$ (TJC/CMU, 3.Of., 1851, Proc.6796. fls.12-15).

A marca "F" descrita pelo avaliador em utensílios de prata, como colheres, garfos e facas referia-se à gravação do sobrenome da ascendência, ou seja, "F" de Florence. À época era comum o uso de monogramas pelas famílias da elite local em louças, talheres e roupas de uso pessoal e da casa (ABRAHÃO, 2010, p. 94).

A participação feminina no aparelhamento dos lares evidenciou-se na análise do rol de bens descritos nos inventários de indivíduos que constituíram família. As quantidades de artefatos ligados à decoração da casa e necessários às ocasiões festivas, assim como ao cotidiano alimentar, corroboram a afirmação e vai ao encontro da observação de Vânia Carneiro de Carvalho (2008, p.22-23; 67-69) de que a integração do corpo feminino ao local de residência possuía ação irradiadora, em cada detalhe - do arranjo de flores sobre a mesa 
Artigos

do hall de entrada, aos bordados nas toalhas que recobriam a escrivaninha, assim como as toalhas de crochê sobre a mesa de jantar - que demonstrava a abrangência da ação da mulher na engrenagem doméstica.

Atuação feminina percebida também na residência de Maria Gertrudes de Sousa Campos, esposa de José de Sousa Campos, filho de Miquelina Dulce do Amaral. Sua casa localizada à Rua Francisco Glicério, número 13, foi mobiliada com o que havia de mais moderno e elegante. De herança da sogra recebeu os castiçais, as serpentinas, as salvas, os trinchantes e os paliteiros, todos de prata, utilizados em jantares formais. A sala de estar atendia aos padrões da época. Para a decoração Maria Gertrudes utilizou espelho oval, mesa de canto com tampo de mármore na qual ficava um relógio de cristal, um sofá, cadeiras de balanço e as de uso comum e o seu piano (ABRAHÃO, 2010, p.101).

Cuidados e recomendações propagados nos manuais de comportamento e administração doméstica de meados do século XIX. Dos "conselhos culinários" ou os também chamados "conselhos úteis", a orientação às futuras donas de casa destacavam aspectos sobre a limpeza da habitação e de roupas, de como aquecer a carne ou evitar que a manteiga ficasse rançosa, reportavam-se às situações nas quais as condutas dos anfitriões, especialmente da anfitriã - eram evidenciadas e conferiam grande destaque à participação da mulher. Entre os preceitos estipulados, ela deveria ser contida, porque dessa maneira demonstrava a capacidade de governar a si, ao seu lar e de manter o controle sobre tudo e todos nos momentos de sociabilidade (ABRAHÃO, 2014, p.218).

Uma mulher - senhora ou senhorita - que soubesse conversar e se portar convenientemente em sociedade cumpriria importante papel, projetando-se como auxiliar de seu marido na articulação e na conservação de alianças econômicas e políticas, concorrendo ainda para a manutenção do prestígio familiar (CARVALHO, 1895). As jovens eram preparadas, em casa ou nos colégios, para o exercício desse papel. Além de ler, escrever e contar, também aprendiam gramática portuguesa e francesa, geografia e música, devendo habilitar-se também nas chamadas "prendas domésticas” (LISBOA, 1870).

No tocante à educação, constata-se que no período estudado havia em Campinas oportunidades de estudos para as moças, com a oferta de escolas e professores particulares aptos a lecionar francês, inglês e latim (FERREIRA e SILVA, 1879). De acordo com Campos Salles, - futuro presidente da República - no ano de 1871, de um total de 570 alunos matriculados na cidade, 200 eram moças, que representavam 35\% da população estudantil. Entre os colégios destaca-se o de Josefina Sarmento, Carolina Florence e de Maria do Céu de Carvalho Lacerda.

O Colégio Nossa Senhora do Patrocínio, na cidade de Itu, era outra opção de ensino. Essa instituição educacional caracterizou-se como uma escola que formava mulheres cristãs, cultas, virtuosas, polidas e sociáveis (PROSPECTO apud CUNHA, 1999, p.93). O currículo contemplava as disciplinas consideradas básicas para uma "boa" educação católica. As matérias de ensino eram: instrução religiosa; gramática portuguesa; aritmética, geografia e cosmografia; noções de botânica natural; noções de física; curso de história sagrada e profana; diversos gêneros de caligrafia; curso de literatura, especialmente o gênero epistolar; francês; trabalhos manuais: todas as espécies de pontos de meias e de costuras; remendos; obras de gosto: "flores artificiais; toda a espécie de bordados e pontos de tapete”. As lições especiais incluíam: língua inglesa e alemã; piano, canto e desenho (CUNHA, 1999, p.100).

Para melhor compreender o significado da educação formal para as jovens campineiras da elite, é importante observar que, uma vez aptas para a leitura e a escrita, elas podiam ter acesso a outras fontes de informação. Os Almanaques, por exemplo, dedicavam várias seções ao público feminino. Destaca-se a publicação de contos com temáticas consideradas na época próprias para mulheres, os anúncios publicitários com a oferta de artefatos de uso pessoal ou destinados à decoração da casa, assim como aqueles de venda de mobílias austríacas, cristais, porcelanas, joias e gêneros alimentícios importados pelos negociantes de Santos, São Paulo e do Rio de Janeiro. Os importadores recebiam esses produtos diretamente dos portos de Liverpool, Antuérpia, Lisboa, na Europa e de Nova York, na América do Norte (PEDRO, 2010, p.73-80). Todo esse arsenal de produtos estava à disposição da clientela feminina nos estabelecimentos comerciais da cidade de Campinas.

Eram as esposas, tias, irmãs, filhas (e as serviçais) que zelavam pela imagem do homem público, autônomo, envolto em questões de política e economia, que na verdade estava rodeado por um grupo de mulheres que o ajudavam a manter sua posição social (D'INCÃO, 1997, p.223-40). Essa sociabilidade, pra- 
ticada nos jantares, adquiria a função de veículo informal pela disputa de cargos e privilégios - por meio dela estreitavam-se alianças financeiras, tramavam-se candidaturas políticas e estabeleciam-se compromissos matrimoniais (SCHAPOCHNIK, 1998, v.3). O oferecimento de jantares aos amigos e pessoas do mesmo círculo de relacionamento passou a ser considerado um dos mais importantes deveres na sociedade nacional da época. Para essas ocasiões havia todo um ritual prescrito, a ser rigorosamente obedecido pelos diversos atores sociais, como mencionado (LIMA, 1995, p.129-191).

Esses detalhes não passaram despercebidos pelas mulheres citadas neste artigo que, atentas ao que se produzia na Europa, possuíam em suas salas de jantar os itens obrigatórios para o banquete, como as cristaleiras e étagere - aparadores do tipo guarda-louça -, além, obviamente, da mesa elástica e suas respectivas cadeiras. O esmero de Braulia Ludgera de Queiroz Sousa, viúva de Francisco de Paula Sousa Campos, em equipar sua residência de acordo com os modelos vigentes pôde ser claramente percebido pela leitura de seu inventário (CAMPOS JR., 1940, p.305-316). Nas salas de sua residência havia:

[...] mobília austríaca preta composta por: sofá, cadeira de balanço, 2 consoles com tampos de mármore, 2 cadeiras de braço e 12 cadeiras simples. Outro conjunto de jacarandá com: sofá, 4 cadeiras de braço, 12 simples, 2 aparadores com tampo de mármore. Os objetos de decoração eram: mesa para vasos de flores; 3 pares de jarros; relógio de parede; lampião belga; 13 quadros de diversos tamanhos; espelho de cristal; 2 almofadas, cortinas e 2 vasos (TJC/CMU, 1.Of., 1895, Proc.6115. fls.51-54.)

Entre os móveis e utensílios ligados à alimentação identificam-se:

[...] guarda louça com portas de vidro; outro com portas de madeira; mesa elástica para jantar; 6 compoteiras sendo uma para doces secos; 2 garrafas para água e uma para vinho; licoreiro; bateria de copos e cálix; paliteiro, farinheira, molheira; um lote de xícaras e pires para chá, café e chocolate; bule, manteigueira, cafeteira e açucareiro (TJC/CMU, 1.Of., 1895, Proc.6115. fls.51-54.)

Afinal, os ambientes dedicados à sociabilidade nas residências dessas famílias da elite cafeicultora estavam materialmente equipados com o que havia de mais moderno, dando respaldo aos rituais e protocolos próprios do ato de alimentar-se, enfatizados nos manuais de etiqueta (ALGRANTI, 2011, p.244-259; ELIAS, 2001).

Não só barões e fazendeiros habitavam a cidade. Casas intermediárias e simples completavam, com os suntuosos sobrados, o cenário urbano das Campinas do século XIX. Observar os espaços de representação social das casas dos comerciantes, médicos, advogados, farmacêuticos, pequenos empresários, possibilitou a comparação do modo de habitar do estrato intermediário da população campineira. ${ }^{4}$

Nas residências dessas camadas populacionais a quantidade de cômodos era menor, mas a preocupação em copiar o luxo e a decoração das casas da aristocracia agrária revelou-se apenas nos casos em que esses personagens constituíram famílias. Como discorrido, as mulheres eram as responsáveis pelo aparelhamento dos lares.

Com relação às casas das famílias menos abastadas, por exemplo, de ferroviários ou de libertos, a descrição do mobiliário e dos utensílios são precárias. Os inventários fornecem pouca informação sobre os móveis existentes, detendo-se em objetos e utensílios de ouro, prata e cobre, por possuírem maior valor relativo. Quanto à construção, eram pequenas, em muitos casos com telhado dito de uma água, com sala, quarto e cozinha onde as refeições eram preparadas e ali mesmo consumidas. Verifica-se que a quantidade de mobília, objetos de decoração e utensílios era mínima, sinal de pouco dinheiro para consumir esses bens e o gasto era com coisas prementes. Entre os objetos estavam canastras - muitas vezes revestidas em couro -, marquesa grossa com armação, catre, armário pequeno para a louça ou simplesmente caixa de vários tamanhos com fechaduras ou não. Os baús de madeira serviam para guardar as roupas e como assentos, na falta de cadeiras.

Evidencia-se no inventário de Anna Joaquina de Sousa a discriminação do avaliador, pois não a tratou como "Dona" - título dado às senhoras da elite - e explicitou a simplicidade e a escassez dos móveis de quarto de propriedade desta senhora. Seu filho, Manoel José de Oliveira, herdou:

4 Prefiro trabalhar com estratos sociais e não com classes sociais, mas autores como Amaral Lapa (2008, p.103) considera esse estrato social como pequena burguesia em ascensão. 
Artigos

um banco largo velho com descanso, $1 \$ 000$; um banco estreito pouco usado $\$ 500$; dois tamboretes muito velhos forrado de couro, $\$ 160$; um bofetinho muito ordinário com uma gaveta sem fixadeira, $1 \$ 500$; três catres usadas, duas tecidas em couro, uma em imbira, $2 \$ 640$; três banquinhos muito baixos e [_?], $\$ 200$; um escovaçador, $\$ 640$; uma módica de quarto, $\$ 320$ (TJC/CMU, 1.Of., 1850, Proc.2798, fl.36).

Anna Cândida de Oliveira teve melhor sorte, pois dentre seus bens achava-se ouro, prata e cobre, de pouca monta:

ouro velho pesando 8 oitavas $80 \$ 000$; prata velha em cabo de faca e em cabo de chicote pesando 8 oitavas $24 \$ 960$; duas escovaçadeiras, $2 \$ 000$; catre usado de cama, $3 \$ 000$; (...) uma caixa maior, $2 \$ 500$; outra caixa "mais" pequena, 1\$000; um armário pequeno, $3 \$ 000$ (TJC/CMU, 1.Of., 1855, Proc.3029, fls.8-9).

As visitas dos amigos à casa de Germano Stefanini com certeza eram bastante breves. A exígua mobília evidenciava o despojamento dos bens materiais. Os bens constam de:

uma pequena casa no bairro Guanabara à rua 1 de Março e de 1 pequeno negócio no mesmo bairro. Casa, quintal sita à rua 1 de Março no bairro Guanabara com uma porta e duas janelas ... assoalhada ... 2:500\$000; uma cômoda, 50\$000; duas mesas de madeira, 20\$000; duas camas [?], 30\$000; duas cadeiras com braços, 40\$000; um armário, $10 \$ 000$ (TJC/ CMU, 2.Ofício, 1905, Proc.5790, fls.4 e 8).

Enfim, a casa campineira foi se transformando conforme a cidade vivenciava seu crescimento econômico. A sociabilidade e as práticas cotidianas demonstravam que os núcleos familiares se refinavam e as pessoas de posses usavam destes elementos para se distinguirem perante seus pares. A partir da cultura material, verifica-se que a riqueza gerada pelo café propiciou o aumento da oferta e do consumo de mobiliário e de objetos de decoração de estilo europeu, de utensílios domésticos mais sofisticados e a construção de modernas casas. Esse aprimoramento na aparência das residências e de seus moradores relacionava-se com a modernização cultural, social e econômica pela qual passava a sociedade campineira.

A mudança, no entanto, não se restringia às elites e nem atingia a todos os segmentos da sociedade. Pessoas de condição econômica intermediária ou inferior partilhavam dessas mudanças nas formas de morar, como a separação de gêneros e a divisão dos papéis sociais. Independentemente da posição social a qual pertenciam, o papel patriarcal, por exemplo, foi preservado em alguns cômodos da casa.

A criação de um ambiente dedicado especialmente às refeições, na casa moderna do século XIX, demonstra a importância dessas ocasiões e seus os rituais à mesa, para os grupos sociais como forma de distinção social. O tempo consagrado à sociabilidade alimentar, seus ritos e códigos se combinaram para formar modelos socialmente diferenciados de grupos ou indivíduos, constituindo uma identidade social afirmada por um estilo de vida próprio que os caracterizavam (GWENAËL apud BOZON, 1982, p.137-146).

O domínio do savoir viure - que implicava ostentar desde o refinamento material, com casas bem aparelhadas e decoradas, até um estilo corporal, por meio de modos elegantes a serem adotados em público, como no ato de receber convidados - reforçava seu pertencimento social. As mulheres foram personagens fundamentais na propagação e perpetuação desses modelos de comportamento ligados ao fazer e ao cerimonial da alimentação. Preocupações com o protocolo de recepção aos convidados para jantares e reuniões - da minúcia de detalhes sobre decoração da casa e da mesa de jantar, aos menus especialmente elaborados para essas ocasiões - ocorriam sob os atentos olhares femininos. Detalhes sobre a vestimenta a ser usada, o arranjo das salas, as instruções à criadagem, entre outros, concorriam para que jantares e festas - os quais demandavam cuidados e inteligência das anfitriãs - ocorressem de maneira impecável e correta. Mas a sociabilidade praticada pela elite campineira por certo não chegou aos lares dos demais estratos da sociedade. As festas, mesmo que significassem um repositório de costumes e tradições que permitiam uma circularidade de novos símbolos e produtos culturais, para as camadas mais pobres da sociedade resumiam-se às festividades religiosas, aos eventos políticos e a enterros de personalidades e às suas próprias reuniões familiares. 


\section{Fontes}

Fundo Tribunal de Justiça de Campinas (TJC) - Centro de Memória - Unicamp (CMU)

Inventários de Ana Matilde de Almeida, 1.Of., 1844, Cx.131, Proc.2460.

Inventários de Braulia L. de Queiroz Souza. 1.Of., 1895, Cx.393, Proc.6115.

Inventários de Cândida Maria Vasconcellos Barros. 3.Of., 1851, Cx.364, Proc.6796.

Inventários de Maria Gertrudes de Sousa Campos. 2.Of., 1909, Cx.267, Proc.5837.

TJC. Inventários de Miquelina Dulce do Amaral. 3.Of., 1863, Cx.394, Proc.6980.

. Fundo Theodoro Sousa Campos Junior. Cadernos de receitas de Anna Henriqueta de Albuquerque Pinheiro. Livro1-3.

\section{Referências}

ABRAHÃO, Eliane Morelli. Morar e viver na cidade: Campinas (1850-1900). Mobiliário e utensílios domésticos. São Paulo: Alameda Editorial, 2010.

. Os receituários manuscritos e as práticas alimentares em Campinas (1860-1940). Tese (Doutorado em História) - Instituto de Filosofia e Ciências Humanas, Universidade Estadual de Campinas, Campinas. 2014.

ABRAHÃO, Fernando Antonio (Org.). Delícias das sinhás: História e receitas culinárias da segunda metade do século XIX e início do XX. Campinas, SP: Unicamp/CMU; Arte Escrita, 2007. (Fernando Kassab: adaptação, preparação e fotografia das receitas; Prefácio de Leila Mezan Algranti).

ALGRANTI, Leila Mezan. Tabernas e botequins. Cotidiano e sociabilidades no Rio de Janeiro (1808-1821). Acervo, v.24, n.2, p.25-42, jul./dez. 2011.

ARAÚJO, Maria Lucília Viveiros. Os interiores domésticos após a expansão da economia exportadora paulista. Anais do Museu Paulista, São Paulo, v.12, p.129-160, jan./dez. 2004.

ARIÈS, Philippe. Por uma história da vida privada. In: ARIÈS, Phillippe; CHARTIER, Roger (Orgs.). História da vida privada: da Renascença ao século das Luzes. Trad. Hildegard Feist. São Paulo: Companhia das Letras, 1999. v.3.

BAENINGER, Rosana. Espaço e tempo em Campinas: migrantes e a expansão do pólo industrial paulista. Campinas: Centro de Memória; NEPPO-Unicamp, 1996. (Coleção Campiniana, 5).

BRAUDEL, Fernando. Civilização material, economia e capitalismo, séculos XV-XVIII. São Paulo: Martins Fontes, 1995. v.1.

BOZON, Michel. La fréquentation des cafés dans une petite ville ouvrière. Une sociabilité populaire autonome? Ethnologie française, n.2, vol.12, p.137-146, 1982. Disponível em: < http://www.insee.fr/fr/ffc/docs ffc/es352-353i. pdf>. Acesso em: 28 jun. 2011.

CAMPOS JR., Theodoro de Sousa. A Família Sousa Campos. Revista Genealógica Brasileira. Instituto Genealógico Brasileiro, ano I, n.2, p.305-316, jul./dez. 1940.

CARVALHO, Maria Amália Vaz de. (1895). Arte de viver na sociedade. Estudo e atualização do texto Isabel M.R. Mendes Drumond Braga e Paulo Drumond Braga. Lisboa: Colares Editora, 2004.

CARVALHO, Vânia Carneiro de. Gênero e artefato: o sistema doméstico na perspectiva da cultura material. São Paulo, 1870-1920. São Paulo: Edusp; FAPESP, 2008.

CERTEAU, Michel de; GIARD, Luce. Espaços privados. In: CERTEAU, Michel de; GIARD, Luce; MAYOL, Pierre. A invenção do cotidiano. 3 ed. Petrópolis: Vozes, 2000.

COSTA, Jurandir Freire. Ordem médica e norma familiar. 5.ed. Rio de Janeiro: Edições Graal, 2004.

CUNHA, Maria Iza Gerth da. Educação feminina numa Instituição total confessional católica Colégio Nossa Senhora do Patrocinio. Dissertação (Mestrado em História) - Faculdade de Filosofia, Letras e Ciências Humanas, Universidade de São Paulo. 1999. 
Artigos

D’INCAO, Maria Ângela. Mulher e família. In: DEL PRIORE, Mary (Org.). História das mulheres no Brasil. São Paulo: Contexto, 1997.

ELIAS, Norbert. O processo civilizador: uma história dos costumes. 2.ed. Rio de Janeiro: Zahar, 1994.

FERREIRA, Carlos; SILVA, Hypolito (Orgs.). Almanach Popular de Campinas para o anno de 1879. Campinas: Typographia da Gazeta de Campinas, [1879].

FREYRE, Gilberto. Ob de casa! Em torno da casa brasileira e de sua projeção sobre um tipo nacional de homem. Rio de Janeiro: Ed. Artenova, 1979.

GAZETA de Campinas, Anno II, n.135, 2/3/1871.

LEME, Luiz Gonzaga da Silva (1852-1919). Genealogia Paulistana. São Paulo: Duprat, 1903-1905.

LIMA, Tania Andrade. Pratos e mais pratos: louças domésticas, divisões culturais e limites sociais no Rio de Janeiro, século XIX. Anais do Museu Paulista, Nova Série, v.3, jan./dez. 1995.

LISBOA, José Maria (Org.). Almanak de Campinas para o ano de 1871. Campinas: Typographia da Gazeta de Campinas, 1870.

PEDRO, Carina Marcondes Ferreira. Casas importadoras de Santos e seus agentes: comércio e cultura material (1870-1900). Dissertação (Mestrado em História) - Faculdade de Filosofia, Letras e Ciências Humanas, Universidade de São Paulo, São Paulo. 2010.

PILLA, Maria Cecília Barreto Amorim. A arte de receber: distinção e poder à boa mesa - 1900-1970. Tese (Doutorado em História) - Faculdade de História, Universidade Federal do Paraná, Paraná. 2004.

PUPO, Celso Maria de Mello. Campinas, seu berço e juventude. Campinas: Academia Campinense de Letras, 1969.

RAINHO, Maria do Carmo Teixeira. A cidade e a moda. Brasília: UnB, 2002.

A distinção e suas normas; leituras e leitores dos manuais de etiqueta e civilidade - Rio de janeiro, século XIX. Acervo, Rio de Janeiro, v.8, n.12, p.139-52, jan./dez. 1995.

RANUM, Orest. Os refúgios da intimidade. In: ARIÈS, Phillippe; CHARTIER, Roger (Orgs.). História da vida privada: da Renascença ao século das Luzes. Trad. Hildegard Feist. São Paulo: Companhia das Letras, 1999. v.3.

SCHAPOCHNIK, Nelson. Cartões postais, álbuns de família e ícones da intimidade. In: SEVCENKO, Nicolau (Org.). História da vida privada no Brasil. República: da Belle Époque à Era do Rádio. Coleção coordenada por Fernando A. Novais. São Paulo: Companhia das Letras, 1998. 3v.

TSCHUDI, J.J. Von. Viagem às provincias do Rio de Janeiro e São Paulo. Belo Horizonte: Ed. Itatiaia; São Paulo: Edusp, 1980. (Coleção Reconquista do Brasil, Nova Série, v.14). 